133.

\section{Natural or Technological Disaster: Proposals for International Medical Teams}

\author{
Dr. J.M. Fonrouge, MD, ${ }^{1}$ G. Fonrouge, Pr. S.W.A. Gunn, ${ }^{2}$ \\ Pr. M. Belanger, ${ }^{3}$ Pr. P. Petzt, $M D^{1}$ \\ ${ }^{1}$ CHU de Lyon, Hôpital E. Herriot 69437-France \\ ${ }^{2}$ WADEM, Genève \\ ${ }^{3}$ Université de Droit de Bordeaux
}

Natural and technological disasters pose serious problems for the organization of emergency assistance.

There are two essential principles:

1) Dispatching and coordinating emergency medical teams; and

2) Directing victims to qualified care units.

The dispatching of medical teams may mobilize the emergency facilities of the country concerned or may involve international humanitarian aid. Coordination of the teams requires not only harmonization of the means of assistance, triage, and care, but also rational forms of communication between the various authorities concerned.

If any governmental or nongovernmental bodies are involved in the organization of emergency assistance, then they must:

1) Be compatible with each other; and

2) Respect the modes of functioning of the authorities from the country concerned by the disaster.

For this reason, it would be useful to set up and manage emergency medical teams on an international level. Such teams could be composed and trained to be able to intervene in any form of disaster. Their techniques and equipment would be similar so as to facilitate effective, rational cooperation between each of the elements.

International coordination for such means would be placed under the aegis of an intergovernmental organization like the $\mathrm{UN}$ or the WHO, but with the guarantee of total neutrality (including neutrality in the media) whenever an intervention is performed. Only such neutrality would enable this form of international medical structure to be called upon in serious disasters. Indeed, it is inconceivable in international health law that a victim should not receive emergency care simply because of poor immediate coordination of the means available, or for political reasons It probably is through the coordination of the various international emergency facilities that international humanitarian aid can become truly effective and, therefore, desired by a country faced with a large-scale disaster.

\section{7.}

\section{The Rwandan Refugee Crisis in Goma, Zaire: The AJJDC Experience}

Richard M. Hodes, MD, Dawit Welday, MD, Tsehay Kibreab, MD

The American Jewish Joint Distribution Committee,

Addis Ababa, Ethiopia

In July 1994, 1 million Rwandan refugees fled to Zaire. Cholera developed, thousands died. In response, A]JDC sent a medical team to Zaire. The initial weeks were spent as combat medics in Kibumba camp treating cholera. By the end of August, this was largely replaced by shigella dysentery I, sensitive only to ciprofloxacin. By November, this was replaced by malaria.

Working under International Rescue Committee of New York, we were assigned $25 \%$ of the Kibumba camp. All persons (approximately 50,000) were registered, given soap, handwashing instructions, and Vitamin A. Also, 40 community health workers were trained to visit each family weekly. All huts were numbered for follow-up. Thousands of latrine platforms were produced and distributed. A 110-bed tent hospital was opened. Over 1,300 patients were admitted from September 1994 through January 1995, including 91 with watery diarrhea, 250 with dysentery (treated with 5 days supervised ciprofloxacin), 262 with pneumonia, and 453 with proven $P$. falciparum malaria.

Of 416 malaria cases treated successfully, response rates were chloroquin $60 \%(n=40)$, pyramethamine-sulfadoxine $87 \%(\mathrm{n}=299)$, quinine $97 \%(\mathrm{n}=132)$, quinine+doxycycline $100 \%(n=4)$. Two patients failed quinine alone, but responded to quinine+doxycycline. Overall hospital death rate was below $5 \%$. Causes of death included malaria (20), pneumonia (10), malnutrition (7), and bloody diarrhea (2). We believe that a significant proportion were HIV+, but none were tested.

The integrated approach of sanitation, curative and public health, along with water delivery to the camp, reduced the death rate significantly.

\section{9.}

\section{Regency Response Units: The Use of A General Field Hospital during the Rwanda Refugee Crisis.}

\section{Dieter Jacobi, Joachim Kreysler}

German Red Cross Society and International Federation of Red Cross and Red Crescent Societies,

Bonn, Germany and Geneva., and Switzerland.

The German Red Cross Society had developed a multipurpose field hospital for use in crisis situations such as large-scale refugee movements. The core unit of the hospital, consisting of surgery, obstetrics, pediatrics, and general medicine originally was designed to serve 50,000 patients with comprehensive district-type referral health. It also provided outpatient services and is equipped with a basic laboratory, a water production unit, and electricity supply. This unit was developed further during 12 months in the Rwanda refugee crisis, being the only referral hospital for a population of 420,000 in the Benaco Camp in Tanzania.

The paper describes the development of the hospital unit during these field activities and gives data on future developments in the context after an emergency response system (ERU) presently designed by the International Federation of Red Cross and Red Crescent Societies and in European member Red Cross Societies. 